\title{
Stroke-like migraine attacks after radiation therapy (SMART) syndrome
}

\author{
Síndrome com crises de migrânea tipo acidente vascular cerebral após radioterapia (SMART) \\ Diaa Hamoudaㄹ, Fábio A. Nascimento², Shiao-Pei Weathers³, Vinodh A. Kumar
}

A 33-year-old, right-handed male with a left occipital hemangiopericytoma treated with resection/radiation (60 Gy) with resultant focal epilepsy, presented with severe left-sided headache, expressive aphasia/right homonymous hemianopsia and right-sided hemisensory deficits. The EEG was unremarkable. Initial MRI brain scans are shown in Figures A and B. He improved with analgesics and returned to his baseline in two weeks. The MRI was repeated after 16 days (Figure C). He was diagnosed with SMART syndrome, a rare and late complication of cranial irradiation ${ }^{1,2}$. The pathophysiology is still unclear. The process seems to be driven by cerebral hyperexcitability with impaired autoregulatory mechanisms and endothelial damage as a consequence of remote radiation ${ }^{1}$. Clinico-radiological features are challenging. Differential diagnosis includes tumor recurrence, leptomeningeal carcinomatosis, infection, vascular disorders, mitochondrial encephalomyopathy with lactic acidosis and stroke, hemiplegic migraine, posterior reversible encephalopathy and post-ictal MRI changes. Duration of symptoms is variable (hours to weeks). Most reported cases have had full clinical and radiological recovery with symptomatic management; however, incomplete recovery may occur².

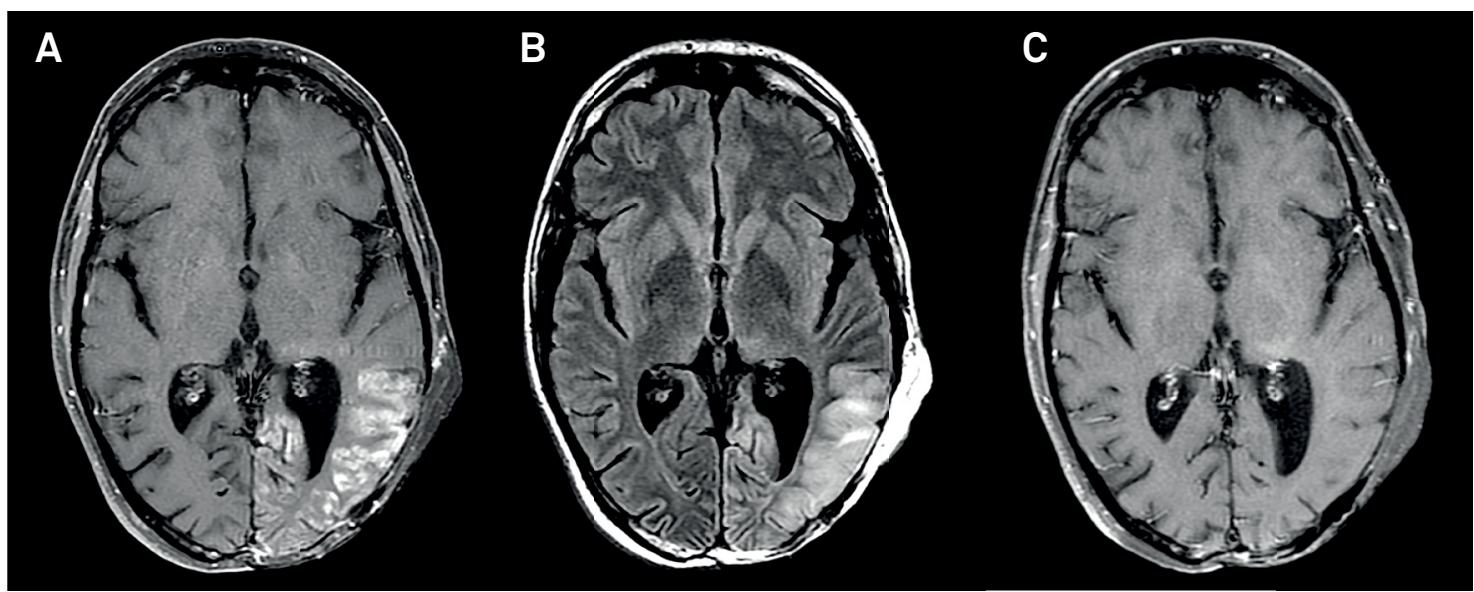

Figure. Axial T1-weighted post-contrast MRI brain image demonstrates unilateral diffuse gyriform cortical enhancement with associated grey matter thickening on axial FLAIR imaging in the left parietal/occipital lobes (A and B). Follow-up MRI brain (16 days later) showed completed resolution of the cortical enhancement (C) and improvement of the FLAIR abnormality (not shown).

\section{References}

1. Kerklaan JP, Lycklama a Nijeholt GJ, et al. SMART syndrome: a late reversible complication after radiation therapy for brain tumors. J Neurol. 2011 Jun;258(6):1098-104. https://doi.org/10.1007/s00415-010-5892-x
2. Black DF, Morris JM, Lindell EP, Krecke KN, Worrell GA, Bartleson JD, et al. Stroke-like migraine attacks after radiation therapy (SMART) syndrome is not always completely reversible: a case series. AJNR Am J Neuroradiol. 2013;34(12):2298-303. https://doi.org/10.3174/ajnr.A3602

1 University of Texas Medical Branch, Department of Neurology, Galveston, TX, USA;

2Baylor College of Medicine, Department of Neurology, Houston, TX, USA;

${ }^{3}$ University of Texas, MD Anderson Cancer Center, Department of Neuro-Oncology, Houston, TX. USA;

${ }^{4}$ University of Texas, Department of Radiology, MD Anderson Cancer Center, Houston, TX, USA.

Diaa Hamouda (iD) https://orcid.org/0000-0003-1007-0996

Correspondence: Diaa Hamouda; University of Texas Medical Branch, 301; Galveston, TX 77555-0539, USA; E-mail: dihamoud@utmb.edu

Conflict of interest: There is no conflict of interest to declare.

Received 02 August 2018; Received in final form 04 October 2018; Accepted 20 November 2018. 